\title{
Activities, Access Control, and Crime: a Quasi-Experimental Study regarding Entry Gates at Train Stations in the Netherlands
}

\author{
Viviane M. Lindenbergh ${ }^{1} \cdot$ Edward R. Kleemans $^{1}$ (D) Joras Ferwerda $^{2}$ (D)
}

Accepted: 10 November 2020 / Published online: 27 November 2020

(C) The Author(s) 2020

\begin{abstract}
This article discusses a unique "natural experiment," the introduction of entry gates at Dutch train stations and the potential effects of this on crime in the areas around these stations. A quasi-experimental study was carried out to show that introducing entry gates correlated with a drop in crime in these areas. After entry gates had been introduced, potential offenders could only enter train stations with a valid ticket, which meant that they would be less likely to enter or leave these stations and more likely to choose other places to hang around in or for entering and leaving trains. A dataset was created in which the crime rates around train stations were registered for each month in the years 2013 through 2018. The changing numbers of travelers at each station were also taken into account, as this variable probably correlates with the amount of crime. A two-way fixedeffects model was run on data for about 260 train stations, with and without entry gates, using the relative crime rate per thousand travelers as the dependent variable. Based on this relative crime rate, the use of entry gates was found to coincide with a decrease of $9 \%$ in crime, compared to a situation without entry gates. This study can inform policymakers about the potential effects of entry gates in particular and about situational crime prevention in general. Moreover, it illustrates how implementing measures at various locations at different moments enables the effectiveness of such measures to be tested more precisely and with more confidence.
\end{abstract}

Keywords Situational crime prevention · Routine activities · Defensible space · Quasiexperimental research $\cdot$ Crime

This article discusses the consequences of introducing entry gates at Dutch train stations. This "natural experiment" started in 2014, when Dutch Railways (NS) started placing entry gates at

Edward R. Kleemans

e.r.kleemans@vu.nl

1 Vrije Universiteit Amsterdam, Amsterdam, Netherlands

2 Universiteit Utrecht, Utrecht, Netherlands 
some train stations, with more stations following later. This provided a unique opportunity for a quasi-experimental study to test the hypothesis that the introduction of entry gates would correlate with a drop in crime in the areas around these stations. The main idea behind this hypothesis was that as potential offenders would only be able to enter these train stations with a valid ticket, they would be less likely to enter or leave these stations and more likely to choose other places to hang around in or for entering and leaving trains.

But although situational crime prevention measures may reduce crime in certain places, they can also lead to crime displacement or to the reverse, i.e., to the diffusion of benefits to other places nearby (see, e.g., Bowers et al. 2011; Johnson et al. 2014). From the start of the "defensible space" approach (Newman 1972), specific situational crime prevention measures have focused on limiting access to particular areas, which means that offenders cannot enter these areas or can only enter at a higher cost. A well-known example relates to gating alleyways, which turned out to reduce the number of burglaries in specific areas (Sidebottom et al. 2017). Various studies have also been done on crime prevention measures (including access control) and safety and security in transit environments, such as railways, subways/undergrounds, trams, and bus stops (for a review, see, e.g., López 1996; Smith and Clarke 2000; Ceccato and Newton 2015). This article adds to this literature by testing the possible crime drop relating to the introduction of entry gates at train stations in the Netherlands.

After reviewing the relevant literature in Section 1, we discuss the methodology used in the study (Section 2). The primary data include a list showing the timing of entry gates being introduced at train stations, the number of travelers per station, and data from Statistics Netherlands (CBS) on registered crime in the Netherlands in the years 2013 through 2018 for specific areas (i.e., postal/ZIP code areas). Crime rates were analyzed using a two-way fixed-effects panel model. The empirical results are presented in Section 3, followed by the conclusion and discussion in Section 4.

\section{Situational Crime Prevention, Train Stations, and Crime}

Renewed interest in the relationship between crime and the built environment was sparked in the 1970s by the publication of Crime Prevention through Environmental Design (Jeffery 1971) and Defensible Space (Newman 1972). Since then, environmental criminology has developed into a thriving field of research, with various subfields of study (for a review, see Bruinsma and Johnson 2018). One of these subfields focuses on safety and security in transit environments such as railways, subways, trams, and bus stops (for a review, see López 1996; Smith and Clarke 2000; Ceccato and Newton 2015, for example).

The early review of this literature by Smith and Clarke (2000) stressed two important conditions for crime on urban public transport-lack of supervision and overcrowded conditions - which make urban public transit stations attractive environments for offenders. These authors also discussed various crime prevention measures aimed at "designing out" crime in these settings.

Many of the early empirical studies focused on the USA, particularly the New York City subway system, which was in disarray in the 1970s and suffering high rates of crime, violence, vandalism, and fare evasion. Reddy et al. (2011) conducted review research into measures designed to reduce fare evasion. They found the New York City Transit Authority to have an elaborate system in place to counter subway fare evasion. This included automatic fare 
collection to physically prevent fare evasion, as well as extensive data collection, and a press strategy that included communicating the measures that had been taken. Subway crime has decreased since 2000, and fare evasion rates are low. Regarding the New York City subway, Weidner (1996) describes how the number of fare evasions went down when regular turnstile entry gates were replaced by larger turnstiles. This study examined pre- and post-intervention data on the number of fare evasion arrests and summonses over a total of 60 months. A station with the large turnstiles was compared to two adjacent stations with regular-sized entry gates and that were similar both in size and traveler numbers. A methodological limitation in this study, however, is that only three stations were researched, and this makes the results less generalizable. The use of police data may also result in numbers reflecting policing policies rather than an actual decrease in fare evasion. Lastly, in the context of train station crime, Phillips and Sandler (2015) found that the incidental closing of train stations in Washington DC for maintenance coincided with a crime drop of $5 \%$ in the vicinity of stations on the same line.

Early European studies suggest that regulating access to public transport stations can reduce fare evasion and possibly other crimes. Clarke (1993) concluded that the underground ticketing system in the London Underground, which only allows travelers access if they have a valid ticket, resulted in the number of fare dodgers decreasing by two-thirds. Meanwhile Webb and Laycock (1992) evaluated pilot projects in different areas of London that aimed to reduce crime and fear in the Underground. The first project was aimed at reducing robbery, the second at reducing theft and assault, and the third at reducing fear. The measures taken as part of these projects ranged from increasing the number of cameras at stations to adding alarm points for passengers in the underground. While the implementation of the measures did not coincide with a decrease in theft and assault numbers, the number of robberies did go down. It was unclear, however, whether this was caused directly by the measures, or by policing and the publicity surrounding the introduction of the measures. The measures did not seem to have any effect on passengers' fear of crime.

Although many countries have faced the same problems and taken similar measures to combat crime, violence, fear, and fare evasion, the main focus of the early published literature was on the USA and the UK. Although this dominance was also present in a more recent collection of studies on safety and security in transit environments (Ceccato and Newton 2015), this latter collection also includes studies conducted elsewhere, specifically Sweden (Stockholm), Japan (Tokyo), and South Africa (Tshwane). Some studies, such as the study relating to the Stockholm Underground, showed that metro stations can be both crime generators and crime attractors (Ceccato and Uittenbogaard 2014). Furthermore, an early study by Gaylord and Galliher (1991) on public transport in Hong Kong examined station design and found that having few entrances and exits contributed to safety by making it harder for criminals to avoid getting caught.

In conclusion, very little research has been done on crime at train stations specifically, while research on other types of transit has focused particularly on subway or underground systems in the USA and the UK. The published research has also tended to focus more on fare evasion than on a wider range of crimes. Lastly, many studies are merely descriptive and lack a strong empirical research design.

Alongside research into the possible relationship between offenders, offender behavior, and the built environment since the 1980s, many practical crime prevention measures have also been proposed, implemented, and evaluated (Welsh and Taheri 2018). One of these measures involves limiting potential offenders' access to specific places. Sidebottom et al. (2017), for 
instance, evaluated the gating of alleyways and concluded that these measures reduced the number of burglaries in these areas.

An important discussion in the literature on situational crime prevention relates to possible displacement effects: crime prevention measures may reduce crime at specific places, but may perhaps also displace crime to other places or times, or result in its replacement by other types of crime. On the other hand, these measures may also lead to the reverse: in other words, to benefits being diffused to other places nearby (see, e.g., Bowers et al. 2011; Johnson et al. 2014). After reviewing theoretical and empirical research, Johnson et al. (2014: 549) concluded that displacement is far from inevitable and that diffusion of the benefits of crime control is at least equally likely: "Successful crime reduction interventions often have a positive impact on crime that extends the direct recipients of a particular project."

Introducing entry gates at train stations can be regarded as a form of situational prevention. More specifically, it involves prevention by environmental design in that it changes the environment and makes it impossible to enter or leave certain areas (including entering and leaving trains at these stations) without a valid ticket. This may also change the routine activities of potential offenders. According to the routine activity theory (Cohen and Felson 1979), crime occurs when three elements converge in time and space: (1) a motivated offender, (2) a suitable target, and (3) the absence of a capable guardian. This theory predicts that less crime will occur if one of these elements is reduced. The main effect of introducing entry gates at stations is that motivated offenders are less likely to frequent these stations as they cannot enter them without a valid ticket.

In 2002, the Dutch Minister of Transport, Public Works, and Water Management (as it was then) presented a plan to improve social safety in areas around public transportation facilities. This included 22 measures aimed at improving the safety of both passengers and employees. One of these measures involved regulating access by introducing entry gates at train stations. In 2014, Dutch Railways (NS) started placing entry gates at various train stations, with more stations following later. By December 2018, entry gates were in use at 76 stations (Parliamentary Papers II, 28642, No. 1 2002; Parliamentary Papers II, 28642, No. 60 2015), while other stations implemented or will implement the measure later.

The measure aims to limit access to train stations for people without a valid entry ticket. In 2015, the Ministry of Infrastructure and Water Management (as it is now called) encouraged municipalities to facilitate the implementation of this measure, originally in response to a violent incident directed at a train conductor at a Dutch station. The Ministry expected entry gates to lead to a decrease in fare evasion, and this in turn to reduce aggression against train personnel. The plan was to place entry gates at stations so that, each day, at least $90 \%$ of passengers would encounter such a gate. Hence, the first entry gates were placed at train stations in large cities or with high numbers of travelers (NS 2018; Parliamentary Papers II, 28642, No. 60 2015). Broekhuizen et al. (2017) concluded that the majority of train passengers expected the use of entry gates to reduce crime.

After these measures were implemented, studies by the NS found the number of fines for fare evasion to have dropped by $34 \%$ in 2018 , compared to 2015 , and the number of incidents involving aggression in trains also to have decreased (Middelkoop 2018). However, the numbers of incidents involving aggression at stations (rather than in trains) were found to have increased. And even though both fare evasion and incidents of aggression in trains seem to have decreased, it is not clear whether this change is significant and whether the introduction of entry gates had any effect on crime in the surrounding areas. 
The introduction of entry gates at train stations can be regarded as an opportunity for a unique "natural experiment" that may affect crime in the areas around train stations. We therefore carried out a quasi-experimental study to test the hypothesis that introducing entry gates would correlate with a drop in crime in the areas around stations. Since the introduction of entry gates, potential offenders have only been able to enter stations with a valid ticket. Our hypothesis was that they would then be less likely to enter or leave these stations and more likely to choose other places to hang around in or for entering and leaving trains. Using a twoway fixed-effects panel model, we analyzed variations in crime rates in specific areas at specific times. We elaborate on our methodology in the next section.

\section{Methodology}

Except for some regional lines in the periphery of the country (and which had often previously been closed down by NS for economic reasons), nearly all railway lines in the Netherlands are operated by NS. As NS was the first to start using entry gates at stations, this analysis focuses only on NS lines and train stations. Information was available on the average number of travelers per station per workday for each year in the periods 2013-2018. Some NS train stations were excluded because they did not open until after 2013, were closed down during the period, or were only used for specific events or, in one case, because of a lack of crime data (one station). ${ }^{1}$ A total of 260 stations were thus available for the analysis (76 with and 184 without entry gates).

For each month in the years 2013-2018, we knew whether or not there was entry gate control (between August 2014 and December 2018, entry gates were put into use at 76 stations) and the number of crimes recorded (see below).

We describe below how we gathered data on crime around train stations, how we constructed the dependent variable (crime per thousand travelers), and why we used a twoway fixed-effects panel model to analyze the data.

\section{Data on Crime Around Stations}

This study used six datasets from Statistics Netherlands (CBS), each containing criminal offenses known by the police to have been committed in 2013, 2014, 2015, 2016, 2017, and 2018, respectively. The periods 2013-2018 was chosen because 2013 was the year before the first entry gates were put into use (August 2014) and data on travelers at each train station were available for that year (measured by electronic passenger control in the form of the $O V$ chipkaart introduced in 2013). For each station, therefore, this time frame included both a period before and after entry gates started being used. To select the offenses falling within our chosen time period, we looked at the date on which each crime was committed. The development of crime over time was analyzed for each month separately, which meant a total

\footnotetext{
${ }^{1}$ The Barneveld Zuid, Boskoop Snijdelwijk, Eemshaven, Maastricht Noord, Nijmegen Goffert, Utrecht Leidsche Rijn, Waddinxveen Triangel, and Zwolle Stadshaven stations were excluded because they opened after 2013, while Heerlen de Kissel was excluded because it closed down in 2018, and Rotterdam Stadion was not included because it is only used for special events. Utrecht Maliebaan station was excluded because no regular trains stop there, and Spaubeek station was excluded because no specific postal codes could be found within one hundred meters of the station.
} 
of 72 months $(6 \times 12)$ being included in the analysis. The data analyzed also included information about the location (postal codes), type of location, and type of crime.

The process of linking offenses to specific train stations entailed several steps. First, the offenses where the postal code in which they were committed was unknown were removed from the data ( $21 \%$ of the data). To link crimes to the various stations on the basis of postal codes (PC6), we checked which postal codes fell within an area of one hundred meters from a station entrance. This distance was chosen because it meant that at least one postal code could be found for nearly every station. We chose not to expand the area because looking at a larger area could have watered down the possible effects of the entry gates. Using a small area would mean that the number of crimes that could be included would be relatively small, and this could result in random fluctuations in crime having a seemingly strong influence. If, on the other hand, the area selected was too large, a small (but real) effect could have been undetectable. When choosing the area of research, we consequently had to make a trade-off between these various considerations. Another factor that may play a role in selecting a certain area size relates to obstacles in the environment. Physical barriers can influence the way crime is distributed throughout the environment (Bowers and Johnson 2003). For practical reasons, the current study used a fixed distance, ignoring the possible existence of any physical barriers. As not only the station but also the area around it was included, it was not possible to examine potential effects displaced to the immediate surroundings. Alternatively, we could have chosen not to take entrances as a starting point for determining the area of research, but instead the center of each station. The reason we did not choose this method was because of the strong variations in the sizes of the different stations. For some stations, one hundred meters from the center would have included only the station building itself, while for others it would also have included a large part of the surrounding environment. Our decision to focus on entrances rather than centers meant that, for every station, the selected area included both the station itself and part of the built environment around the station. It should be kept in mind that Dutch postal code areas vary in size and shape, and thus the number of postal codes linked to a specific station depends on the type of area. In the analysis, however, stations were compared to themselves at different moments in time, which had the advantage that structural differences between the stations did not distort the outcome of the analysis. It is only if the differences between stations varied over time that this factor could have distorted the outcome.

We used Google Maps to determine the coordinates of the station entrances. These coordinates were subsequently used to determine the surrounding postal codes. This was done using Overpass turbo, a data mining tool for OpenStreetMap. The resulting list of postal codes was used to register the name of the corresponding station for each crime recorded within one of those postal code areas. Ultimately, the dataset contained a total of 141,753 offenses for analysis.

\section{Dependent Variable: Crime per Thousand Travelers}

We used publicly available data on the number of travelers (from Treinreiziger.nl) to construct the dependent variable (crime per thousand travelers). These data were used in the analysis to correct for the effect that the number of travelers might have on crime. According to routine activity theory, most crime can be expected at places where most potential victims and offenders come together. By correcting for the number of travelers when analyzing the amount of crime, we improved the measurement of the effect we were actually interested in: the effect of the entry gates. 
Crime data are often presented in relation to the population size in a certain area. However, other measurements have been proposed for estimating the actual number of people residing in a certain area (the ambient population), although population size is usually related to the ambient population. Which type of data can best be used depends on the specific situation (Andresen and Jenion 2010). For this specific situation, the number of travelers was considered to be the most relevant.

As we focused on NS stations, it had to be kept in mind that some stations were used by more than one transport company, and that only the NS passengers were to be included in the data. The number of travelers was primarily estimated based on public transport chip card $(\mathrm{OV}$ chipkaart) data. But as the way in which numbers of travelers were measured in the periods 2013-2018 was not constant, the data have to be regarded as estimation rather than an exact measurement, especially in the first few years. The data used is related to passengers boarding or exiting at a certain station on an average workday in a specific year. This did not include transfer passengers (Treinreiziger.nl 2019). The number of travelers was not known for every station in every year. Missing values were filled in, based on the assumption that the numbers developed linearly over the years. ${ }^{2}$ As the number of travelers was only available as an annual average, no account was taken of fluctuations in passenger numbers during the year. This could make the results of the analysis less accurate. For example, if the actual number of travelers decreased over the year, crime would also be expected to decrease. Using a constant number of travelers could then make the crime rate per thousand travelers seem to be decreasing, while in reality this would not have been true. However, we expect this effect to be limited because the current study used data from multiple years and many different stations. The annual data on the number of travelers were used predominantly to correct the crime data for the size of the train station being considered.

\section{Analytical Strategy: Two-Way Fixed-Effects Panel Model}

A two-way fixed-effects panel analysis was used to determine the effect of introducing entry gates. A panel model can be used when data are available for different moments in time for the same research units. Panel data combine cross-sectional and longitudinal data, with categorization based both on the individual research units and on the different moments in time. In contrast to using only cross-sectional data, panel data make it possible to examine the individual development of the different research units over time. Units can thus be compared to themselves at different moments in time. Because this time-related information can be analyzed, the assumptions needed when using a panel model are less far-reaching.

Normally, the assumption of exogeneity applies; i.e., the values of variables are assumed not to correlate with the error terms. In the case of the current study, however, this assumption could already be predicted to be false. There was a selection effect because entry gates were placed specifically at stations with high numbers of travelers (Parliamentary Papers II, 28642, No. 60 2015), and most crimes are likely to be committed at busy stations (for the same reason, our final analysis looked not at the absolute number of crimes, but instead at the crime rate per thousand travelers). The crime rate at a specific station also depends on the way the postal codes are selected. However, panel data allow us to look at the development of the individual

\footnotetext{
${ }^{2}$ A slightly different calculation was made for the Enschede Kennispark station (near the University of Twente and a soccer stadium). As the number of travelers in 2018 was much lower than in the previous years, the year 2018 was excluded when calculating the missing values for 2013 and 2014.
} 
research units over time, and to assess how much the value at a specific moment in time deviates from the average value of that unit. The two-way fixed-effects model controls for all time-constant differences between stations. However, differences between units that fluctuate over time could still distort the effect we wanted to measure (Brüderl and Ludwig 2015).

The final analysis used a two-way fixed-effects panel model. A one-way model looks only at research units for which the value of the independent variable changes over time: in other words, only the "experimental group" is examined, and not the "control group." This has the disadvantage that the effect could be distorted by a development caused by omitted variables. For example, crime may have been decreasing over the years independently of the entry gates. If, therefore, we only looked at stations with entry gates, we might wrongly conclude that the entry gates were what caused the drop in crime, while, in reality, this could have been due to factors not included in the analysis. A one-way panel model operates under the assumption of temporal homogeneity. That assumption can be weakened by not only looking at the "experimental group," but by also including the "control group" in a two-way fixed-effects model. The analysis then looks at the variation in the error terms of the research units, compared to the average trend over time of all the research units (Brüderl and Ludwig 2015).

The analysis was conducted in Stata (version 14.0). The Kolmogorov-Smirnov test demonstrated that there was no normal distribution $(p<0.001)$. At many stations, there were months in which no crimes were reported. The value " 0 " occurred in $26.6 \%$ of the time points. Such a distribution is not uncommon in criminological research: crime is relatively rare if measured on a small scale. The analysis chosen for the current study was based on a Poisson distribution, which is often used for analyzing rare events (Bijleveld et al. 2015).

\section{Empirical Results}

\section{Descriptive Analysis}

The full dataset for all train stations in the Netherlands contained 141,753 offenses. Most crime was found near Amsterdam Central (10,431 offenses), Utrecht Central (5295 offenses), and The Hague Central (3871 offenses) stations. The ten most common crimes (based on the standard crime classification code; CBS 2011) are shown in Table 1. The most frequent crime was bicycle theft $(41.7 \%)$. Over $80 \%$ of the data are in one of these ten categories. Accordingly, if entry gates affected specific crimes from these categories, this would have a major influence on the outcome of our analysis. In Table 1, the crimes not fitting within these ten categories are grouped together in "all other categories" (17.0\%). This category includes serious crimes such as manslaughter, or very specific crimes such as theft from a vessel. The dataset used for the final analysis only contained data for the 260 stations used by the NS (instead of 384); a total of 128,151 offenses were committed at these stations. The percentages represented by these different types of crime are almost identical to those in Table 1.

Table 2 shows the main characteristics of the variables used in the analysis. The average number of travelers each workday per station was 9300 (NS passengers only). The average number of criminal offenses around stations in the periods 2013-2018 was 369, which meant 5.1 offenses per station per month. In general, the number of crimes was found to be decreasing over time. This trend is shown for the NS stations in Fig. 1 (see Fig. 3 in the Appendix for a similar trend for all stations). The number of crimes seems to fluctuate through the seasons, peaking in September and October, and dropping around February each year. This 
Table 1 Number of registered crimes per category

\begin{tabular}{lll}
\hline Crime & Frequency & Percentage \\
\hline Bicycle theft & 59,161 & 41.7 \\
Theft and burglary (other) & 18,865 & 13.3 \\
Pickpocketing & 11,183 & 7.9 \\
Shoplifting & 8624 & 6.1 \\
Assault (Arts. 300-306 Dutch Criminal Code) & 4260 & 3 \\
Destruction or damaging of other objects & 3539 & 2.5 \\
Theft from and out of passenger cars & 3332 & 2.4 \\
Theft from and out of mopeds & 3219 & 2.3 \\
Threatening & 2793 & 2 \\
Theft from and out of other vehicles & 2645 & 1.9 \\
All other crime categories & 24,132 & 17 \\
Total & 141,753 & 100 \\
\hline
\end{tabular}

pattern seems roughly in line with many other studies that found crime to peak in the summer (see, e.g., Cohn and Rotton 2000; Dodge 1988; for an overview, see McDowall et al. 2012). Taking the research period as a whole, the highest number of crimes was found to have been committed in September 2013 (2568), and the lowest in December 2018 (1358).

The number of travelers increased between 2013 and 2018, both for NS stations with entry gates and for those without entry gates. However, there was a substantial difference between the increases at NS stations with entry gates and those without entry gates: a 5.0\% increase in travelers (compared to 2013) at stations without entry gates versus a $13.6 \%$ increase at stations with entry gates. Stations with entry gates accounted for the majority of travelers: $65.1 \%$ (in 2018). The annual average number of travelers per workday per station varied between 142 (Maastricht Randwyck station in 2018) and 194,385 (Utrecht Central station in 2018). Figure 4 in the Appendix shows how the number of travelers developed over the years, both at stations with and stations without entry gates.

For the analysis on which this article is based, the number of crimes per station per month was divided by the number of travelers (and multiplied by 1000). Figure 2 shows the development of the crime rate per thousand travelers. The crime rate for stations with entry gates was found to be relatively low, mainly owing to the high number of travelers at these stations, compared to stations without entry gates.

Table 2 Descriptive statistics for the main variables

\begin{tabular}{|c|c|c|c|c|c|}
\hline & Mean & Range & $\mathrm{SD}$ & $\mathrm{n}$ & $\%$ of total \\
\hline $\begin{array}{l}\text { Number of incidents per station } \\
\text { per month }\end{array}$ & 5.1 & $0-205$ & 11.1 & & \\
\hline $\begin{array}{l}\text { Average number of travelers on a } \\
\text { workday per station per year }\end{array}$ & 9299.9 & $142-194,385$ & 19,981 & & \\
\hline $\begin{array}{l}\text { Number of incidents per station } \\
\text { per month per thousand } \\
\text { travelers }\end{array}$ & 1.2 & $0-62.1$ & 1.8 & & \\
\hline Stations with entry gates & & & & 76 & $\begin{array}{l}19.8 \text { (29.1 if only } \\
\text { NS stations } \\
\text { included) }\end{array}$ \\
\hline Stations without entry gates & & & & $\begin{array}{r}308 \text { (185 if only NS } \\
\text { stations included })\end{array}$ & $\begin{array}{l}80.2 \text { (70.9 if only } \\
\text { NS stations } \\
\text { included) }\end{array}$ \\
\hline
\end{tabular}




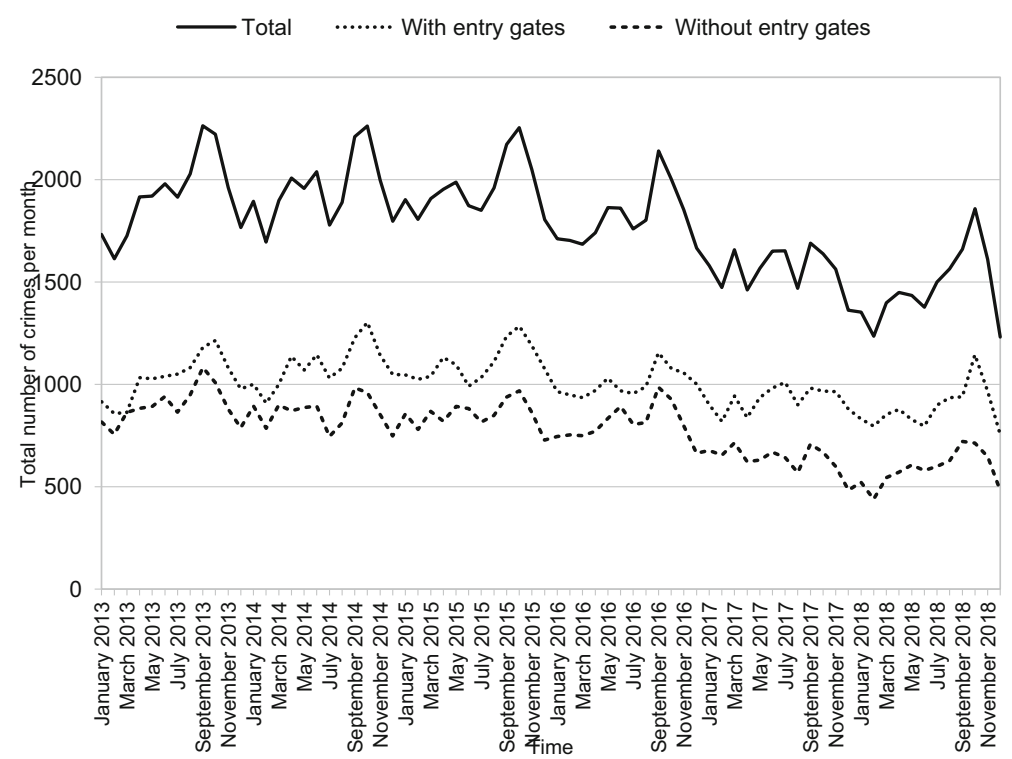

Fig. 1 Total number of crimes per station per month (only the 260 NS stations), broken down into stations with and stations without entry gates

Table 3 shows the Pearson correlation coefficients for the following variables (for 260 NS stations): the total number of offenses; whether a station had entry gates at any point in time; whether the entry gates were in use at that specific moment; the point in time; the number of offenses per thousand travelers; and the number of travelers. Table 3 shows a weak negative correlation between time and the number of offenses. The number of offenses per thousand

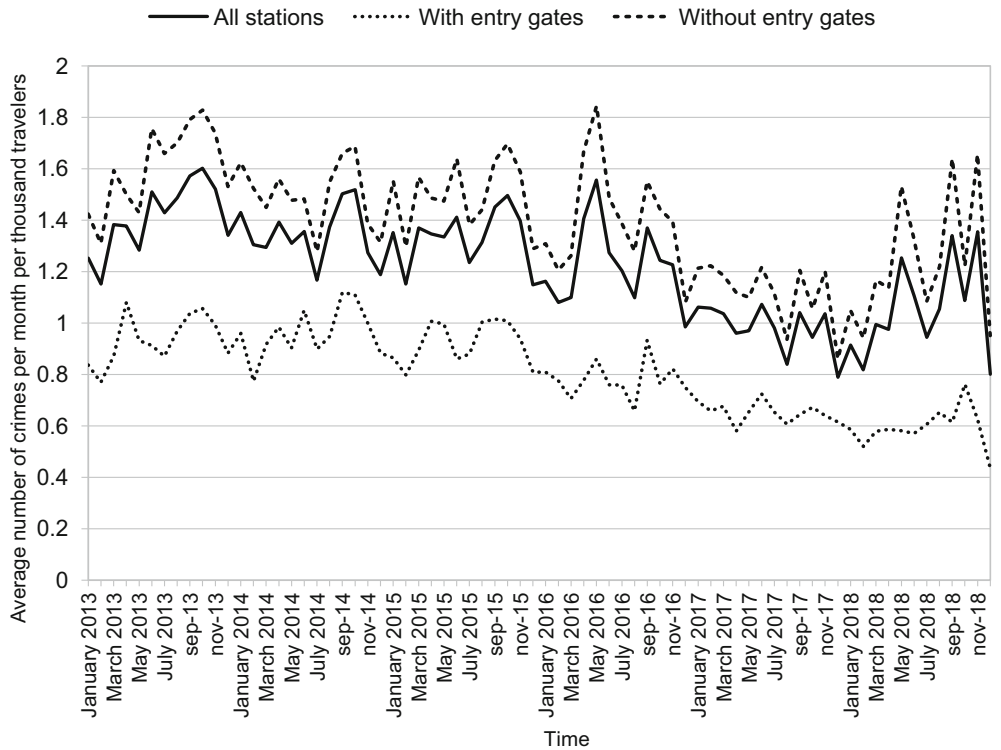

Fig. 2 Average number of crimes per station per month per thousand travelers, broken down into stations with and stations without entry gates 
Table 3 Pearson correlation coefficients

\begin{tabular}{|c|c|c|c|c|c|c|}
\hline & $\begin{array}{l}\text { Total number } \\
\text { of incidents }\end{array}$ & $\begin{array}{l}\text { Entry } \\
\text { gates }\end{array}$ & $\begin{array}{l}\text { Entry } \\
\text { gates in } \\
\text { use }\end{array}$ & $\begin{array}{l}\text { Time } \\
\text { point }\end{array}$ & $\begin{array}{l}\text { Number of incidents } \\
\text { per thousand travelers }\end{array}$ & $\begin{array}{l}\text { Number of } \\
\text { travelers }\end{array}$ \\
\hline \multicolumn{7}{|l|}{$\begin{array}{l}\text { Total number of } \\
\text { incidents }\end{array}$} \\
\hline Entry gates & $0.32 * *$ & & & & & \\
\hline Entry gates in use & $0.14 * *$ & $0.65 * *$ & & & & \\
\hline Time point & $-0.048 * *$ & 0 & $0.30 * *$ & & & \\
\hline $\begin{array}{l}\text { Number of incidents } \\
\text { per thousand } \\
\text { travelers }\end{array}$ & $0.055^{* *}$ & $-0.15 * *$ & $-0.11 * *$ & $-0.076 * *$ & & \\
\hline Number of travelers & $0.84 * *$ & $0.37 * *$ & $0.19 * *$ & $0.017 *$ & $-0.12 * *$ & \\
\hline
\end{tabular}

$*_{p}<0.05 ; * * p<0.01$

travelers also correlated negatively with time. The crime rate was found thus to be decreasing over time. As expected, a strong positive correlation was found between the number of travelers and the number of offenses. Furthermore, a positive correlation was found between the number of offenses and the presence of entry gates. Lastly, a positive correlation was found between the number of travelers and time, as seen in the increase in passengers shown in Fig. 4 in the Appendix.

These descriptive analyses show why it is important to correct for the number of travelers, given that entry gates are often placed at busier train stations with increasing numbers of travelers over time (which also affects the amount of crime). Below, therefore, we present findings for the crime rate per thousand travelers.

\section{Two-Way Fixed-Effects Panel Model}

A two-way fixed-effects panel analysis was performed for the $260 \mathrm{NS}$ stations with the relative crime rate per thousand travelers as the dependent variable (the number of crimes per month divided by the number of travelers and multiplied by 1000). This allowed us to identify the effect of implementing entry gates by comparing stations with entry gates with a control group of stations without entry gates, while correcting for all time-constant differences between stations. Looking at the relative crime rate, we found the use of entry gates to coincide with a crime drop of $9 \%$, compared to a situation without entry gates. This effect is significant at the $1 \%$ level $(p=0.007$; IRR $=0.91 ;$ CI $0.85-0.98){ }^{3}$

\section{Conclusions and Discussion}

This article focuses on a unique "natural experiment," the introduction of entry gates at train stations in the Netherlands, and the potential effects that these gates have had on crime in the surrounding areas. We carried out a quasi-experimental study to test the hypothesis that the

\footnotetext{
${ }^{3}$ Additionally, the same analysis was performed for only the most common type of crime around train stations: bicycle theft. This gave a similar result. The use of entry gates was found to coincide with a drop of $10 \%$ in the relative number of bicycles thefts, compared to a situation without entry gates $(p=0.035$; IRR $=0.90$; CI $0.81-$ $0.99)$.
} 
introduction of entry gates would correlate with a drop in crime in the areas around these stations. This was because after the gates had been introduced, potential offenders were only able to enter train stations if they had a valid ticket. We hypothesized, therefore, that they would be less likely to enter or leave these train stations and more likely to choose other places to hang around in or for entering and leaving trains. We used a two-way fixed-effects panel model to analyze variations in crime rates in specific areas at specific times.

A dataset was created in which the crime rates around train stations were registered per month in the years 2013 through 2018. We also took the changing numbers of travelers at each station into account because this variable correlates with the amount of crime around stations. We ran a two-way fixed-effects model for 260 NS stations with and without entry gates, using the relative crime rate per thousand travelers as the dependent variable (the number of crimes per month divided by the number of travelers and multiplied by 1000). When looking at this relative crime rate, the use of entry gates was found to coincide with a drop of $9 \%$ in recorded crime, compared to a situation without entry gates. This therefore corroborated the original hypothesis that the introduction of entry gates would reduce crime rates around stations.

These findings align with the existing literature on situational prevention and may be explained by changes in the routine activities of potential offenders. Routine activity theory (Cohen and Felson 1979) predicts that crime occurs when three elements converge in time and space: (1) a motivated offender, (2) a suitable target, and (3) the absence of a capable guardian. Entry gates can change one of these elements (i.e., the presence of motivated offenders) because the gates mean motivated offenders cannot enter these areas without a valid ticket. The findings are also in line with a previous study by Van Andel (2018), which concluded that the entry gates at Dutch train stations brought about a decrease in crime. As well as methodological differences, Van Andel (2018) selected crimes at specific types of locations that could logically be located at train stations. Van Andel's research also selected crime primarily based on address, and secondarily on postal code. For many train stations, therefore, that study included a smaller surrounding area. Both studies, however, concluded that the introduction of entry gates reduces crime.

This study can help policymakers make more informed decisions on the use of entry gates at stations in particular and on the potential effects of situational crime prevention methods in general. It also illustrates that where measures aimed at situational crime prevention are implemented at different locations at different moments in time, researchers can test the effectiveness of such measures more precisely and with more confidence.

An important limitation of this study is that the introduction of entry gates at stations was part of a more comprehensive plan to reduce fare evasion and aggression. Therefore, these entry gates were not the only measure implemented in recent years. Other measures included the increased use of cameras and additional staff, with the introduction of entry gates being combined with extra surveillance to ensure that people did not bypass the newly placed entry gates (Abraham et al. 2016). Because these measures are directly linked to the use of entry gates, it is hard to distinguish between the effect of entry gates and the effect of the additional surveillance.

\section{Strengths and Weaknesses}

This study used a large amount of data: all crimes registered by the police. The specific dates on which the crimes took place were registered in the CBS datasets. As the specific dates of implementing entry gates were also available, we could analyze the monthly crime rate per 
station. We were also able to combine the unique opportunity of a "natural experiment" with the strong methodological design of a two-way fixed-effects panel model to compare research units over time, both with and without entry gates.

A possible limitation is that this study looked only at registered crime, while it is likely that not all crime is registered. The amount of crime registered depends very much on people's willingness to report crime and press charges. Van de Weijer and Bernasco (2016) found that the willingness to report crime increased slightly over the years 2005-2015, while the willingness to press charges decreased over that period. The willingness to report crime and the willingness to press charges correlate, among other things, to the type of crime and location. However, our two-way fixed-effects panel analysis corrected for differences between stations and, therefore, also for differences in reporting rates. It may be that differences would only be problematic if reporting rates for different locations changed differently over time, and if this was related to the presence or absence of entry gates. Given, however, that entry gates were introduced across the country and there is no sound theoretical and empirical backing for different developments over time, we do not consider this to be a convincing alternative interpretation of our empirical findings.

This study is not a classical experiment. Hence, no strong conclusions can be drawn regarding causality. We used the largely objective criterion that crime in postal codes within a range of one hundred meters from a station entrance is relevant. Because this criterion was the same for every station, the trends at the various stations can be compared relatively well. However, the way the postal codes were selected also entailed some disadvantages. To start with, our selection meant a large area around the station was included. A hypothetical displacement effect in the immediate surroundings could, therefore, have gone unnoticed. Furthermore, crime might not have displaced to the immediate surroundings but instead to more distant areas, which this study did not include. As mentioned before, the crime rates are not suitable for meaningful comparisons between stations, given that the type of area around the station determined which postal codes were included, and this in turn determined the amount of crime linked to the specific station. A benefit of using a two-way fixed-effects panel model, however, is that this type of analysis looks at the trends at individual stations over time. Furthermore, both an 'experimental group' and a 'control group' were constructed (i.e., stations with entry gates and stations without entry gates, respectively). In principle, therefore, the results were not influenced by static structural differences between stations.

The analysis consequently represents an important step towards finding a causal link and goes beyond the research designs used in earlier studies. Not only was a correlation established, but an alternative explanation - that the effect we found was caused by systematic differences between stations - was ruled out. Differences between research units can potentially change over time, and this type of variation can still affect the outcome when using this analysis. Account was taken of one of those varying factors: the average number of travelers per station per workday throughout the years.

\section{Future Research}

Future research could include other crime data, such as victim surveys or incidents registered by Dutch Railways. This latter source could provide insight into the exact location of the crime, given that it is known, for example, whether crimes were committed in a train or at the station. Including more data will in any event provide insight into the precise effects of entry gates. This could enable identification, for example, of how different types of environments 
affect the crimes committed. The development of crime in an urban area may possibly differ from that in a rural area. More information about the train stations could also enable the effect of entry gates to be tested using a synthetic control method, such as a robustness test, to append the result found in this article.

Future research could also focus on the effect that entry gates have on different types of crime, given that these gates may affect certain types of crime more than others.

Lastly, it would be interesting to study a possible displacement effect to nearby stations. To study such an effect, the stations on specific train routes could be compared when entry gates are placed at one of the stations on the route. According to Newton (2004), the way that crime spreads across a public transport network depends on the specific type of transport. The effect of entry gates may, therefore, vary between different types of public transport.

Acknowledgments This article is based on a collaboration between Vrije Universiteit Amsterdam (Prof. Dr. Edward R. Kleemans), Utrecht University (Dr. Joras Ferwerda), and Statistics Netherlands (CBS). The authors are grateful to Statistics Netherlands (in particular: Heike Goudriaan, Masja van Rooij-Kooiman, and Nathalie Boot) for providing both data and support and to former VU-student Femke Van Andel for carrying out the first phase of this project during her internship at Statistics Netherlands.

\section{Appendix}

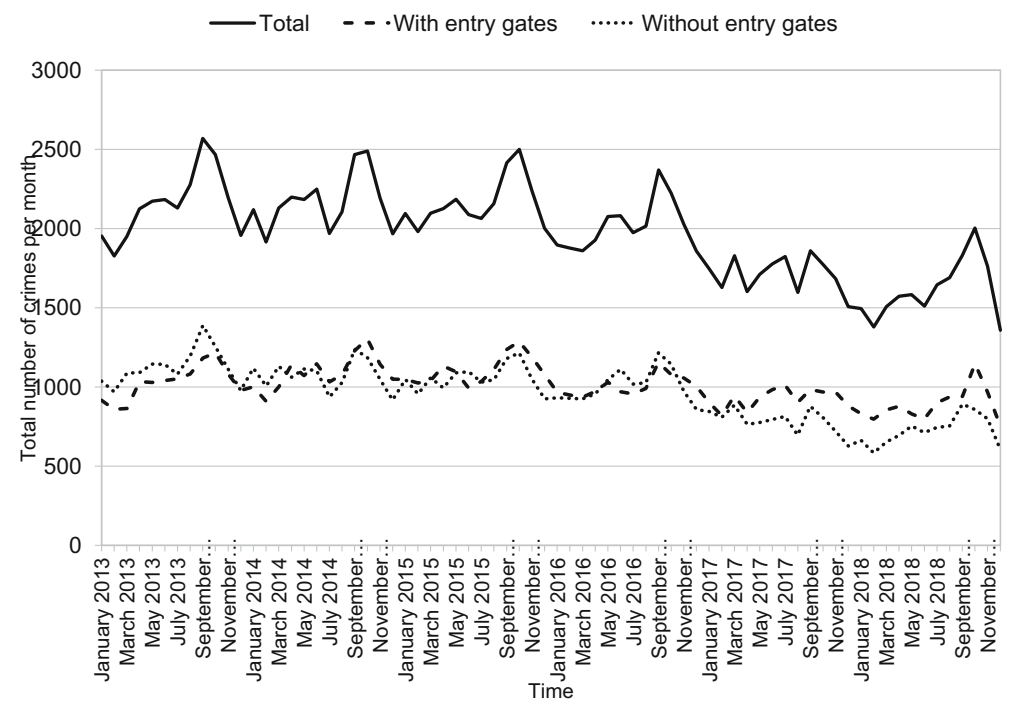

Fig. 3 Total number of crimes per station per month, broken down into stations with and stations without entry gates 


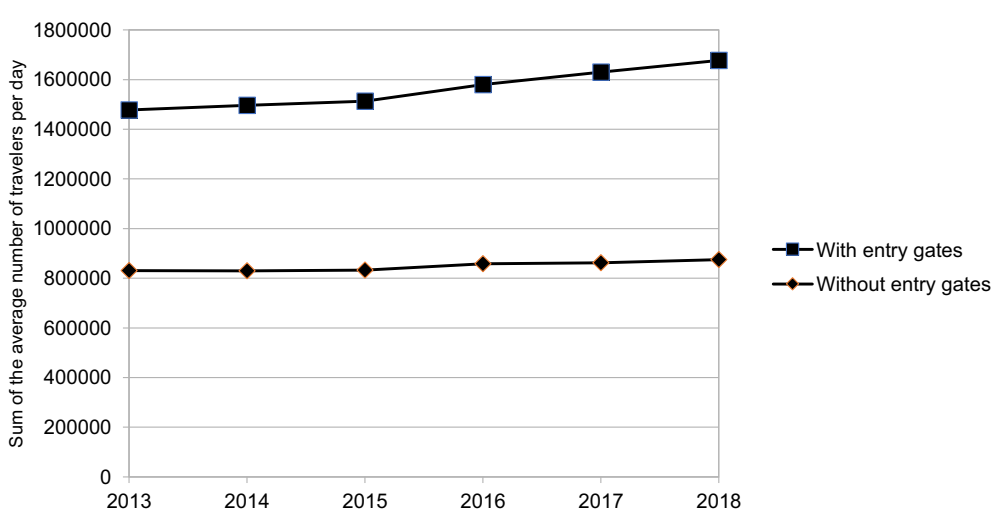

Fig. 4 Average number of travelers per workday for all stations with and all stations without entry gates

Open Access This article is licensed under a Creative Commons Attribution 4.0 International License, which permits use, sharing, adaptation, distribution and reproduction in any medium or format, as long as you give appropriate credit to the original author(s) and the source, provide a link to the Creative Commons licence, and indicate if changes were made. The images or other third party material in this article are included in the article's Creative Commons licence, unless indicated otherwise in a credit line to the material. If material is not included in the article's Creative Commons licence and your intended use is not permitted by statutory regulation or exceeds the permitted use, you will need to obtain permission directly from the copyright holder. To view a copy of this licence, visit http://creativecommons.org/licenses/by/4.0/.

\section{References}

Abraham, M., Egmond, P. van, Roorda, W. and Soomeren, P. van (2016). Sociale veiligheid op het spoor: Quickscan maatregelenpakket verbetering sociale veiligheid in treinen en op stations. Retrieved May 13, 2020, from https://www.wodc.nl/binaries/2692-volledige-tekst tcm28-74403.pdf.

Andresen, M. A., \& Jenion, G. W. (2010). Ambient populations and the calculation of crime rates and risk. Security Journal, 23, 114-133.

Bijleveld, C., Van de Weijer, S., Ruiter, S., \& van der Geest, V. (2015). Analysetechnieken voor nietexperimentele gegevens. The Hague: Boom Lemma uitgevers.

Bowers, K., \& Johnson, S. (2003). Measuring the geographical displacement and diffusion of benefit of crime prevention activity. Journal of Quantitative Criminology, 19(3), 275-301.

Bowers, K., Johnson, S., Guerette, R., Summers, L., \& Poynton, S. (2011). Spatial displacement and diffusion of benefits among geographically focused policing initiatives: A meta-analytical review. Journal of Experimental Criminology, 7(4), 347-374. https://doi.org/10.1007/s11292-011-9134-8.

Broekhuizen, J., Mehlbaum, S., \& Van Kapel, M. (2017). Vervolgevaluatie sociale veiligheid op en rond het spoor. Utrecht: Verwey-Jonker Instituut.

Brüderl, J., \& Ludwig, V. (2015). Fixed-effects panel regression. In H. Best \& C. Wolf (Eds.), The SAGE handbook of regression analysis and causal inference (pp. 327-357). London: SAGE Publications.

Bruinsma, G. J. N., \& Johnson, S. D. (Eds.). (2018). The Oxford handbook of environmental criminology. Oxford: Oxford University Press.

CBS (2011). Standaardclassificatie Misdrijven 2010. Retrieved May 13, 2020, from https://www.cbs.nl/nl-nl/ onze-diensten/methoden/classificaties/misdrijven/standaardclassificatie-misdrijven-2010.

Ceccato, V., \& Newton, A. (2015). Safety and security in transit environments. In An Interdisciplinary Approach. Basingstoke / New York: Palgrave Macmillan.

Ceccato, V., \& Uittenbogaard, A. (2014). Space-time dynamics of crime in transport nodes. Annals of the Association of American Geographers, 105, 131-150. 
Clarke, R. V. (1993). Fare evasion and automatic ticket collection on the London Underground. In R. V. Clarke (Ed.), Crime prevention studies (Vol. 1, pp. 135-146). Monsey (NY): Criminal Justice Press.

Cohen, L. E., \& Felson, M. (1979). Social change and crime rate trends: A routine activity approach. American Sociological Review, 44, 588-608.

Cohn, E. G., \& Rotton, J. (2000). Weather, seasonal trends and property crimes in Minneapolis, 1987-1988. A moderator-variable time-series analysis of routine activities. Journal of Environmental Psychology, 20(3), $257-272$.

Dodge, R. W. (1988). The seasonality of crime victimization. Washington, D.C.: US Department of Justice, Bureau of Justice Statistics, May 1988, NCJ-111033, pp. 1-14.

Gaylord, M. S., \& Galliher, J. F. (1991). Riding the underground dragon; crime control and public order in Hong Kong's mass transit railway. The British Journal of Criminology, 31(1), 15-26.

Jeffery, C. R. (1971). Crime Prevention Through Environmental Design. Beverley Hills: Sage.

Johnson, S. D., Guerette, R., \& Bowers, K. (2014). Crime displacement: What we know, what we don't know, and what it means for crime reduction. Journal of Quantitative Criminology, 10, 549-571.

López, M. J. J. (1996). Crime prevention within metro stations. European Journal on Criminal Policy and Research, 4, 113-119.

McDowall, D., Loftin, C., \& Pate, M. (2012). Seasonal cycles in crime, and their variability. Journal of Quantitative Criminology, 28(3), 389-410.

Middelkoop, A. (2018). Minder zwartrijders in de trein. Retrieved May 13, 2020, from https://nieuws.ns.nl/ minder-zwartrijders-in-de-trein/.

Newman, O. (1972). Defensible space. Crime prevention through Urban Design. New York: Macmillan.

Newton, A. (2004). Crime on public transport: 'static' and 'non-static' (moving) crime events. Western Criminology Review, 5(3), 25-42.

NS (2018). Dagelijks passeren circa $90 \%$ van alle reizigers de poortjes op 75 beheerst toegankelijke stations. Retrieved August 9, 2019, from https://www.ns.nl/binaries/_ht_1539786395451/content/assets/ns-nl/ stationsinformatie/overzicht-stations-met-gesloten-poortjes.pdf.

Parliamentary Papers II, 28642, No. 1 (2002). Retrieved May 13, 2020, from https://www.parlementairemonitor. nl/9353000/1/j9vvij5epmj1 ey0/vi3akrwbjwzu.

Parliamentary Papers II, 28642, No. 60 (2015). Retrieved May 13, 2020, from https://zoek. officielebekendmakingen.nl/kst-28642-60.html.

Phillips, D. C., \& Sandler, D. (2015). Does public transit spread crime? Evidence from temporary rail station closures. Regional Science and Urban Economics, 52, 13-26.

Reddy, A. V., Kuhls, J., \& Lu, A. (2011). Measuring and controlling subway fare evasion: Improving safety and security at New York City Transit Authority. Transportation Research Record, 2216(1), 85-99.

Sidebottom, A., Tompson, L., Thornton, A., Bullock, K., Tilley, K., Bowers, K., \& Johnson, S. D. (2017). Gating alleys to reduce crime: A meta-analysis and realist synthesis. Justice Quarterly, 35(1), 55-86.

Smith, M., \& Clarke, R. (2000). Crime and public transport. Crime and Justice. A Review of Research, 27, 169233.

Treinreiziger.nl (2019). Aantal in- en uitstappers per station bij NS 2013-2018 [Dataset]. Retrieved May 13, 2020, from https:/www.treinreiziger.nl/aantal-in-en-uitstappers-per-station-2013-2018/.

Andel, F. van (2018). Veiligheid in stationsomgevingen: Het effect van het sluiten van toegangspoortjes op stations (Master's thesis, unpublished).

van de Weijer, S., \& Bernasco, W. (2016). Aangifte- en meldingsbereidheid: Trends en determinanten. Amsterdam and The Hague: NSCR and Ministry of Security and Justice/WODC.

Webb, B., \& Laycock, G. (1992). Reducing crime on the London underground: An evaluation of three pilot projects. Crime prevention unit paper 30. London: Home Office.

Weidner, R. R. (1996). Target-hardening at a New York City Subway station: Decreased fare evasion - At what Price? In R. V. Clarke (Ed.), Preventing Mass Transit Crime, Crime Prevention Studies (Vol. 6, pp. 117132).

Welsh, B. C., \& Taheri, S. A. (2018). What have we learned from environmental criminology for the prevention of crime? In G. J. N. Bruinsma \& S. D. Johnson (Eds.), The Oxford Handbook of Environmental Criminology (pp. 757-775). Oxford: Oxford University press.

Publisher's Note Springer Nature remains neutral with regard to jurisdictional claims in published maps and institutional affiliations. 